\title{
RINGKASAN MATERI DAKWAH FILSAFAT \\ SYEKH YUSUF AL-MAKASSARY
}

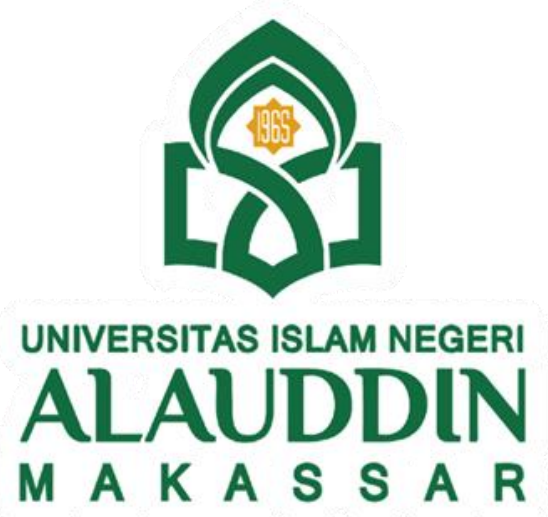

\author{
Disusun oleh: \\ Nama : Rabiatul Adwiyah \\ Nim : 50400121033 \\ Semester/Kelas : 1/MD-A
}

Dosen pembimbing: Prof. Dr. Mustari Mustafa, M.Pd

Jurusan Manajemen Dakwah

Fakultas Dakwah dan Komunikasi

Universitas Islam Negeri Alauddin Makassar

2021/2022 


\title{
AGAMA DAN BAYANG-BAYANG ETIS
}

\author{
SYEKH YUSUF AL-MAKASSSARY
}

\section{BAB I}

PENDAHULUAN

Sikap dan perilaku yang menyimpang bisa dijumpai dalam kehidupan bernegara. Tata hukum dan tata negara disinyalir cenderung berpihak pada kepentingan penguasa. Tampaknya, sistem demokrasi yang ada hanya dinikmati oleh penguasa. Dalam konteks ini, korupsi, kolusi, nepotisme, pelanggaran hukum, dan pelecehan kemanusiaan oleh penguasa didesain dengan sistem dan mekanisme yang samar di mata public (Mustari Mustafa,2011:1).

Bangsa Indonesia telah merumuskan etika yang mengatur hubungan manusia dengan Tuhan dan hubungan manusia dengan manusia dalam falsafah negara, yakni Pancasila. Pancasila sarat dengan nilai - nilai agama yang ada. Etika di dalam filsafat Pancasila tidak sama dengan etika filsafat sekuler. Nilai - nilai Pancasila sarat dengan etika, dirumuskan berdasarkan nilai - nilai universal dari beberapa agama yang ada di Indonesia, sehingga permasalahan manusia tercakup dalam kelima sila tersebut (Lasiyo dan Yuwono,1985:16)

Sistem demokrasi di era globalisasi berdampak pada perubahan nilai nilai etika dan perkembangan kebudayaan. Penerimaan masyarakat terhadap globalisasi dengan unsur modernisasinya cenderung dianggap sebagai gaya hidup dan ukuran kemajuan(Fuad Hassan,2001:53-144). Bahkan ketidakadilan, ketidakpedulian etika sosial dan keagamaan, hukum dalam bermasyarakat baik antarnegara maupun di dalam negara dinilai tidak mempunyai motivasi agama, tetapi lebih pada wilayah ekonomi. Namun, justifikasi agama digunakan oleh sebagian kelompok bagi tindakan yang melanggar etika sosial dan keagamaan(Rafik Issa Beekun,2004:63-64)

Kontradiksi antara ajaran yang baik/benar di dalam agama dengan realitas kehidupan masyarakat, akhirnya memunculkan pertanyaan yang berkaitan dengan sejarah: bagaimana agama dikembangkan di dalam masyarakat? Keberhasilan ajaran-ajaran agama untuk menegakkan etika, dalam sejarahnya, tidak dapat dipungkiri. Akan tetapi, faktor-faktor kegagalannya juga perlu dicermati, terutama pada saat ini. Tampaknya agama belum memperlihatkan caranya dalam mengatasi krisis tersebut. Yang terjadi justru banyak pertentangan yang disertai dengan klaim kebenaran (truth claim) oleh kelompok-kelompok agama sendiri, sehingga 
mencederai ajaran agama yang secara historis dikembangkan melalui misi etis(Mustari Mustafa,2011:4)

Beberapa kendala tentang moralitas bangsa antara lain: Pertama, krisis moralitas yang ditunjukkan oleh banyaknya organisasi dakwah dan individu yang berorientasi pada kepenting an kelompok dan anggotanya. Kedua, di lingkungan umat Islam sendiri, dakwah sebagai aspek yang melekat dalam pengembangan dan pengamalan agama, kurang memiliki citra yang kuat dalam menerapkan nilainilai filosofis dakwah rasul. Sebab, bentuk dakwah Islam di Indonesia cenderung apatis-skeptis, retoris, dan show of force(Mustari Mustafa,2011:5)

Secara umum, semua agama, khususnya Islam menekan kan pentingnya etika religius dalam kehidupan sehari-hari(M. Amin Abdullah, 2004). Dalam literatur-literatur etika dasar, ada empat alasan tentang penting nya etika religius. Pertama, masyarakat yang semakin pluralistik, termasuk aspek moral. Banyak ajaran moral saling berhadapan dan seringkali bertentangan, karena adanya truth claim. Kedua, masa transformasi di bawah hantaman gelombang modernisasi. Transformasi di semua bidang menantang nilai-nilai budaya, sehingga etika religius diperlukan agar manusia tidak kehilangan orientasi. Ketiga, proses perubahan sosial, budaya, dan moral tidak jarang dimanfaatkan oleh pihak-pihak tertentu untuk memancing di air keruh. Keempat, bagi kalangan agamawan, etika religius berfungsi untuk menemukan dasar kekokohan iman(Mustari Mustafa, 2011: 6)

Faktor-faktor penting pada perkembangan dakwah pada masa Syaikh Yusuf yaitu melekatnya dakwah Islam dengan tradisi, strata dan latar belakang masyarakat. Hal tersebut menyebabkan perbedaan status sosial singgah intensitas dan pemahaman keagamaan menjadi beragam. Bahkan latar belakang pendidikan yang tidak sama, baik dari jenis pendidikan, perlakuan pendidikan (treatment), dan faktor status pelaku dakwah, yakni menyangkut kapasitas, kapabilitas, kualitas, dan profesionalitas, secara personal ataupun institusional, turut mempengaruhi kesadaran dan partisipasi keberagamaan masyarakat(Mustari,1995).

Syaikh Yusuf adalah tokoh tasawuf dari Makassar yang berpengaruh dan berperan dalam pengembangan dakwah Islam (Ahmad Purwadaksi, 2001:335), sehingga namanya disebut juga Syaikh Yusuf Taj al-Khalwaty al-Makassary (Cawidu, 1994:1). 


\section{BAB II}

\section{BIOGRAFI SYEKH YUSUF AL-MAKASSARY}

\section{DAN KARYA-KARYANYA}

Sejak kecil Syaikh Yusuf hidup di lingkungan yang agamis dan kecenderungannya pada bidang kerohanian dan spiritualitas Islam. Puang Rama menulis, pada usia 3-4 tahun, Syaikh Yusuf mulai mempelajari huruf al-Quran hingga tamat dan menyempurnakan tajwid dan qira'at dengan fasih kepada seorang guru yang bernama Daeng Ri Tasammang. Pada usia 8-9 tahun, Ia melanjutkan pelajaran ilmu agama Islam kepada seorang ulama besar Mufti Haramayn Makkah dan Madinah yang bernama as-Syaikh Sayyid Baa Alwi Assegaf bin Abdullah al-Allaamatuttahir Assegaf di Bontoala Makassar. Sang Mukti datang ke Sulawesi Selatan pada tahun 1625 M, ialah orang pertama yang membuka Pendidikan Agama Islam di Bontoala pada tahun 1635 M (Puang Rama, S. Djamaluddin Assegaf, 1994). Menginjak usia 16-17 tahun, Syaikh Yusuf berkunjung ke Cikowang Takalar untuk belajar ilmu tasawuf pada ulama besar yang bernama as-Syaikh Sayyid Jalaluddinal-Aidid dari Hadramaut lewat Aceh pada tahun 1646 M. Peran kedua gurunya di Bontoala dan Cikowang inilah yang mendorong Yusuf berangkat ke Mekah. Berbekal surat pengantar dari kedua gurunya itu, Syaikh Yusuf menghadap Mukti Makah Imam Syafi'i untuk belajar hingga mencapai puncak intelektual dan spiritual yang tinggi sebelum di tiba di Makah, Syaikh Yusuf singgah di Banten, lalu ke Aceh (Mustari Mustafa, 2011:22).

Keinginan Syaikh Yusuf untuk belajar patut dijadikan teladan. Meskipun derajat ilmunya sudah tinggi, Syaikh Yusuf tidak berhenti menuntut ilmu. Jika terjadi penyimpangan, Syaikh Yusuf tidak segan-segan untuk menyampaikan pandangan atau kritiknya, meşkipun, misalnya, di lingkungan istana, tempat ia dibesarkan. Syaikh Yusuf langsung menemui raja dan berdialog dengan tujuan untuk mengingatkan raja. Jika raja tidak mengikuti pendapatnya, Syaikh Yusuf meminta izin untuk hijrah dengan ulasan unluk memperdalam ilmu (Mustari Mustafa, 2011:30).

Syaikh Yusuf tidak mengenal lelah menuntut ilmu. Di manapun, Syaikh Yusuf mengajarkan kehidupan yang seimbang antara kebutuhan jasmanI dan rohani, dahaga intelektual dan biologis secara halal dan benar. Meskipun memiliki derajat tersendiri dan menjadi sufi andal, Syaikh Yusuf tetap rendah hati. la bukan seorang sufi yang ekstrem, melainkan sufi moderat yang menguasai ilmu lahir dan batin, tetap membumi dan merakyat. la menjadi mufti kerajaan sekaligus tokoh pejuang melawan penjajajan kolonial (Mustari Mustafa, 2011:30). 
Adapun beberapa naskah atau karya-karya Syaikh Yusuf adalah diantaranya sebagai berikut:

\section{Al-Barukat al-Sailaniqyah Minal Futuhat ul-Rabbuniuuah}

Naskah ini berisi ajaran-ajaran etika dalam berdzkir kepada Allah, tujuan dan makna zikir, macam-macam zikir, cara-cara berdzikir.

\section{Biduvutul Mubtadi}

Naskah ini menjelaskan tentang prinsip-prinsip kepercayaan (keimanan) dalam islam, utamanya tentang keimanan kepada Allah SWT., kitab-kitab-Nya, malaikat-malaikat-Nya, nabi-nabi-Nya, dan qada' dan qadlar. Naskah ini juga menekankan pentingnya kepercayaan atan keimanan bagi seorang muslim sebelum mendalami ajaran-ajaran islam.

\section{Al-fawaih al-Yusufiyyah fi Bayan Tahqiq al-Sufivvah}

Naskah ini menjelaskan hakikat sufi, yaitu seseorang yang telah mencapai pengetahuan mendalam tentang Allah, dengan melaksanakan syari'at secara lahir dan batin. Selain itu, naskah ini juga membicarakan tentang syarat-syarat seseorang dapat mencapai derajat kewalian, yaitu dengan membersihkan hati dari segala penyakit hati dan cinta dunia. Untuk itu, hal penama yang harus dilakukan adalah melakukan zikir terusmenerus sehingga merasakan kehadiran Allah dan meyakini bahwa Allah akan menjadi penolong di dunia dan akhirat. Jelasnya, naskah ini menjelaskan jalan yang hanıs ditempuh oleh seseorang yang ingin mendalami tanpa meninggalkan syari'at, sehingga tidak menyimpang dari inti ajaran islam. (Tudjimah, 1997: 34-38).

\section{Hasyiah fi Kitab al-Anbah fi I'rabi La ilaaha illallah}

Menjelaskan makna kalimat tauhid La ilaaha illa Allah. Menurut orang-orang yang tidak meyakini keesaan tuhan (kafir), terdapat bendabenda lain yang dapat digunakan untuk mendekatkan diri kepada tuhan yang paling tinggi. Padahal, hanya Allah-lah yang dapat rneinberi manfaat dan mudarat (Tudjimah, 1997:110).

\section{Kifiyat al-Munji wal itsbat bi al-Hadis al-Qudsi}

Menerangkan tentang dzikir dan etika dalam berdzikir, penjelasan tentang manfaatmanfaat dan sebab-sebab pentingnya berdzikir kepada Allah. 


\section{Matalib Salikin}

Membicarakan tiga hal penting, yaitu tauhid, makrifat, dan ibadah. Untuk memudahkan para pembaca dan muridnya, Syaikh Yusuf memberikan perumpamaan tentang ketiga hal tersebut sebagai sebuah pohon. Ketiganya merupakan satu kesatuan yang integratif dalam menuju Tuhan. Syaikh Yusuf menganalogikan tauhid sama dengan pohon, makrifat seperti dahan dan daunnya, serta ibadah seperti buahnya. Bagi siapa saja yang ingin mcmahami hakikat ketuhanan dan menjadi muslim yang sempurna, ketiga hal tersebut harus dipahami dengan baik dan benar. Seseorang dapat menuju tuhan dengan melaksanakan seluruh perintah dan menjauhi larangan-Nya berlandaskan ilmu tauhid. Dalam kitab matalib salikin, Syaikh Yusuf menekankan arti pentingnya memahami tauhid agar tidak jatuh dalam kemusyrikan. (Tudjimah, 1997:49-72; Naskah Arab, Bundel A:101).

\section{Al Nafhah al Saylaniyah Menurut tudjimah}

Naskah ini merupakan ringkasan dari tulisan-tulisan syaikh yusuf yang membahas tentang kondisi sesorang saat menuju Allah, seperti fana fillah atau baqa billah, yaitu tentang keadaan leburnya jiwa seseorang salik dalam prosesnya mencapai makrifat kepada Tuhan. (Tudjimah, 1990:7276; Yusuf, Naskah Arab, Perpuskataan Nasional RI).

\section{Tokoh-tokoh yang berpengaruh terhadap karya syekh yusuf}

Tokoh-tokoh yang berpengaruh dalam karya-karya Syaikh Yusuf adalah Ibrahim bin Adham, Imam al-Ghazali, Ibnu 'Ataillahal-Iskandari, Abdul Qadir Jailani, Abdul Karim al-Jilli, dan Rabiahal-Adawiyah

Imam al-Ghazali, lahir di Tus Iran, adalah tokoh yang sering disebut dalam karya-karya Syaikh Yusuf. Ia seorang ulama yang terkenal menekankan harmonisasi tasawuf dan syari'a tserta membela kaum sufi dari tuduhan yang mengatakan kaum sufi tidak peduli pada syari'at (fiqh).

Abdul Karim al-Jilli. Nama lengkapnya adalah Abdul Karim Qutbuddin ibnu Ibrahim al-Jiili. Dilahirkan dari keluarga sufi agung, Syaikh Abdul Qadir Jailani. Al-Jilli lahir tahun 767 H (1366 M) di Jailan dan wafat tahun $832 \mathrm{H}(1430 \mathrm{M})$. Al-Jilli dinilai sangat berpengaruh 
dalam tulisan Syaikh Yusuf, dengan konsepnya al-Insan al-Kamil atau manusia sempurna. Beberapa kali dalam

karyanya Syaikh Yusufmembahas tentang konsep ini,dan menyebut-nyebut al-Jilli sebagai seorang yang memformulasikan konsep tasawuf falsafi.

Rabiah al-Adawiyah adalah seorang sufi perempuan, yang suci dan agung. Dia sangat dimuliakan oleh para sufi pada zamannya karena pengetahuan dan ibadahnya

Rabiah adalah sufi pertama dalam tasawuf yang mengajarkan konsep cinta, yang membimbing seorang sufi di jalan mistis dan hanya melalui jalan cinta, seseorang akan sampai pada tingkat kesempurnaannya 


\section{BAB III}

\section{PENUTUP}

Syaikh Yusuf dikenal sebagai figur dai, ahli tarekat, sekaligus ulama syari'at yang andal. Sebagai sufi besar, ia menguasai dan mengamalkan ajaran Islam secara menyeluruh dan telah mencapai puncak pendakian spiritual tertinggi dalam suluknya, sehingga menjadi wali yang suci dan karomah, bahkan ia berperan juga dalam persoalan sosial dan politik. Ia menjadi tokoh ulama di Kerajaan Islam Makassar, mufti di Kerajaan Islam Banten, juga pejuang yang memiliki patriotisme besar melawan kedzaliman penjajah di Nusantara, bahkan menjadi tokoh yang berpengaruhdi berbagai negara. Syaikh Yusuf adalah salah satu mujadid terpenting dalam sejarah Islam di Indonesia. Jejaknya meliputiwilayah yang sangat luas, dari Sulawesi Selatan dan Jawa Barat, sampai ke Arabia, Sri Lanka, dan Afrika Selatan.

Teori-teori etika religius yang dikembangkan Syaikh Yusuf bersumber dari Al-Qur'an, tentang manusia dan kedudukannya di alam semesta. Etikanya didasari pada pandangan dunia Al-Qur'an, sunnah, konsep-konsep teologi, kategori-kategori filsafat, dan sufisme. Unsur utama pemikiran etika ini berpusat pada duniadan manusia. Sistem etika ini muncul dalam bentuk yang kompleks, yaitu teosentris, antroposentris, dan kosmosentris. Bangunan konsep Syaikh Yusuf merupakan perpaduan antara unsur akal (rasio), rasa (estetis), dan kehendak (etika yang berbasisilahiah).

Konsepsi Syaikh Yusuf tentang Tuhan (teologi) bercorak sintesis antara paham ta'thil (pengosongan Tuhan dari sifat-sifat) dan paham tasybih. Mengenai alam semesta (kosmologi), tampaknya Syaikh Yusuf terpengaruh oleh para pemikir sebelumnya. Hakikat alam adalah tidak ada. Yang ada hanya Tuhan yang menciptakan. Karena itu, semua yang diciptakan oleh Yang Ada hanya penampakan lahir (tajali) dari Tuhan. Sementara tentang manusia (antropologi), Syaikh Yusuf mengatakan bahwa hakikat manusia adalah bayangan Tuhan di muka bumi. Namun demikian, antara Tuhan dan hamba harus tetap ada perbedaan. Hamba tetap hamba betapa pun ia telah sampai ke puncak kesatuan dengan Tuhan, dan Tuhan tetap Tuhan meskipun Dia turun kepada hambaNya. Manusia yang seperti ini disebut sebagai insan kamil. Konsep insan kamil Syaikh Yusuf terfokus pada esensi kesucian, yakni spiritual manusia yang akan 
mengantarkanmanusia ke alam ilahiah (alam ketuhanan), melalui potensi batin yang dimilikinya sebagai indikasi kesempurnaan spritualnya. Konsep-konsep seperti ini adalah sesuatu yang batin (dalam), bahwa perkembangan dimensi batin manusia harus diupayakan melalui perjalanan rohani yang sangat berat (mujahadat) dan latihan spiritual yang terus-menerus (riyadah), karena dimensi batin manusia merupakan hakikat dirinya. Idealisasi kesempurna- an manusia merujuk pada diri Nabi Muhammad Saw. dari sisi kesempurnaan jiwanya dalam merefleksikan sifat-sifat ketuhanan. Dengan mencontoh perilaku Nabi, manusia dimungkinkan dapat memanifestasikan pola relasinya dengan Tuhan dan dengan etika kebudayaan yang sempurna. Dalam rangka pendakian menuju ke maqam insan kamil, manusia harus merujuk pada syari'at, tarekat,hakikat, dan makrifat. Tingkatan-tingkatan tersebut terintegrasi ke dalam suatu sistem ajaran keberagamaan sehingga meniscayakanmanusia menuju tujuan final, yakni jiwa yang siap menerima Tuhan, dan manusia pun mampu mengenal Tuhannya secara sempurna.

Dalam konteks dakwah Islam di Indonesia, kajian tentang etika religius Syaikh Yusuf dapat menjadi acuan yang perlu dikembangkan guna merumuskan ulang paradigma-paradigma filsafat dakwah yang lebih baik, misalnya dakwah etis dalam kaitannya dengan masyarakat non-Islam. Jika mengingat dunia global dan interaksi masyarakat yang makin intensif dalam memenuhi kebutuhan hidup, tentunya masyarakat membutuhkan pandangan dan sikap yang lebih bersahabat, memberi kenyamanan dan ketenangan. Karena itu, etika religius penting dipraktikkan di dalam kehidupan sehari-hari, terutama dalam proses dakwah Islam. 


\section{Daftar Pustaka}

Mustafa, Mustari. Agama dan bayang-bayang etis Syaikh Yusuf al-Makassari. LKIS PELANGI AKSARA, 2011.

https://books.google.com/books/about/Agama_dan_Bayang_Bayang_Etis_Syaikh _Yusuf.html?id=mhReDwAAQBAJ 